\title{
Physical performance and body mass index in Swedish children and adolescents
}

\author{
Ekblom Örjan 1,2, Oddsson Kristjan ${ }^{3}$ and Ekblom Björn ${ }^{1,2}$
}

IÅstrand Laboratory of Work Physiology, University College of Physical Education and Sports (GIH), Stockholm, Sweden; ${ }^{2}$ Department of Physiology and Pharmacology, Karolinska Institutet, Stockholm, Sweden; ${ }^{3}$ Department of Neuroscience, Laboratory for Biomechanics and Motor Control Karolinska Institutet, Stockholm, Sweden

Abstract

Background: Physical fitness and overweight are both important health-related parameters. Reference data from a population are important for comparisons with children with impairments, different diseases, in habilitation or rehabilitation after injuries.

Objective: The aim of the survey was to obtain reference data on physical performance in Swedish children and adolescents aged 10,13 and 16 years. In addition, height and body mass were assessed and body mass index (BMI) was calculated.

Design: In total, 2118 children and adolescents in 48 randomly selected schools in Sweden were invited and 1737 subjects participated. Testing procedures were similar to the Eurofit tests, but with some modifications. Results: Results show generally better performance in boys than in girls and increasing performance with age. BMI increased with age with only small differences between genders. Large variations were found within age and gender groups.

Conclusions: The present study provides reference data on physical performance and body size in Swedish children and adolescents. The results from the present study may be used to compare performance and anthropometric data over time or between countries, to evaluate performance in different patient groups or to set goals for athletes.

Keywords: cardiovascular; neuromuscular; paediatric; physical fitness; Sweden

Received: 25 Aug. 2005; Revised: 15 Oct. 2005; Accepted: 28 Oct. 2005

\section{Introduction}

Physical fitness is a frequently used diagnostic tool when evaluating the physical status of different paediatric patient groups (1-3) or healthy children $(4,5)$, or in different types of intervention studies. Reference data concerning body size [height, body mass and body mass index (BMI)] in children or adolescents may be used in similar situations. Although relevant, earlier studies exist (6-8), recent reference data on healthy Swedish children are currently lacking, making comparisons and evaluations difficult.

To be useful, levels of fitness in a population should either be linked to some form of endpoints (such as health-related outcomes) or be compared with other populations (geographically or over time). In children, however, health complications of overweight or low levels of physical fitness are delayed for many years. Therefore, comparisons are more interesting. Some reference data on physical fitness from other Scandinavian samples are available, for example in a large sample of Norwegian men aged 18-19 years (9) and in Danish children (10). In Sweden, regional data are available on children, but not from nationwide samples. Physicians, physiotherapists, physical education teachers and sport coaches are groups potentially interested in such reference data.

Test batteries for physical fitness have been in use for many years, in studies such as the Leuven Longitudinal Study on Lifestyle, Fitness and Health $(11,12)$ and the Amsterdam Growth and Health Longitudinal Study $(13,14)$.

The aim of the study was to assess physical performance data in a representative sample of Swedish children and adolescents, using tests similar to the Eurofit test battery (15). 


\section{Methods}

The selection process of the Swedish School-SportsHealth (SIH) study has been described in detail elsewhere (16). In brief, in 200148 schools were randomly selected from a national register of schools. Unlike the earlier study (16), data are presented here from the entire survey. All children in the third, sixth and ninth grades in the selected schools were invited to participate in the study, giving a total of 2118 invited children. The mean age of the subjects was 9.8, 12.8 and 15.8 years, for grades 3, 6 and 9, respectively. They are hereafter referred to as 10,13 and 16 years old, respectively. Of these, 1737 subjects participated. Reasons for not participating were illness ( 82 children), holiday (16 children), no parental permission (six children) or other causes, such as religious concerns or disability (eight children). The remaining 269 children were either not interested or absent without known reason. Measurements took place at three specially arranged test centres, with the same trained staff performing the tests. Before the data collection, a parent of each participating child gave written consent. The ethics committee at Karolinska Hospital approved the study (KS 00-416).

\section{Anthropometric measurements}

Height and body mass were recorded with subjects dressed in light clothing, without shoes, using calibrated a standard scale and stadiometer. Height was recorded in centimetres, with one decimal. Body mass was recorded in kilograms, with one decimal. BMI was calculated as body mass in kilograms divided by height in metres squared $\left(\mathrm{kg} \times \mathrm{m}^{-2}\right)$.

\section{Flexed arm hang}

This was performed with a supinated handgrip (palms towards the chest) with chin clear of the bar (the "correct" position). Subjects were helped into the correct position. The bar used had a diameter of approximately $3 \mathrm{~cm}$. Results were recorded as time (seconds, with one decimal) in the correct position. To compensate for differences in body mass, results are given in seconds multiplied by body mass ${ }^{1 / 3}$ according to dimension analysis $(17-19)$

\section{Sit-ups}

The test was performed with a knee angle of $90^{\circ}$ and the feet fixed to the floor. The number of completed sit-ups (from a complete horizontal position on the floor to the position where the elbows touched the knees) during a $30 \mathrm{~s}$ period was recorded.

\section{Vertical jump}

Hands were held on the hips during the jump test. Jump height was measured as the vertical movement of the hip. A measuring tape was attached to a belt running around the subject's waist. The measuring tape then ran under a plastic profile attached to the floor. Subjects were asked to jump vertically. Jump height was calculated as the difference in reading on the measuring tape before and after the jump, to the nearest $0.5 \mathrm{~cm}$. The best out of three tests was recorded. Vertical jump height was multiplied by body mass, thus measuring the maximal functional work capacity, in kilojoules $(\mathrm{kJ})$.

\section{Quiet stand}

The task in the quiet stand test was to balance for $60 \mathrm{~s}$ on one leg standing on a $3 \mathrm{~cm}$ wide steel profile. The subjects were instructed that the free foot must not touch the other foot, but could otherwise move freely. A brief test (3-5s) was done to decide which leg to use, whereafter the test began. If the subject lost their balance, the clock was stopped and started again when the subject did the next ascent. The number of ascents was recorded.

\section{Sit-and-reach}

During the sit-and-reach test subjects sat with straight legs performing a maximal trunk flexion, aiming to reach as far forward as possible. Ankles were kept at a $90^{\circ}$ angle. Reaching distance was recorded as centimetres past the toes, where the value " 0 " denoted having just reached the toes.

\section{Grip strength}

Subjects were asked to compress maximally the handles of the grip dynamometer (Cardionics AB, Bromma, Sweden) for $2-3 \mathrm{~s}$, using their preferred hand. Grip size was adjusted to fit the subjects' hand size, using the middle phalanx on the index finger of the preferred hand. The test was performed with the arm straight down and the dynamometer not touching the body. Three attempts were given and results were recorded in kiloponds $(\mathrm{kp})$ with one decimal [CE1]. The best trial was used for analysis. 


\section{Cycle ergometry}

Heart-rate response to a submaximal work rate on a Monark ergometer was used to estimate cardiovascular fitness. Cadence was set to $50 \mathrm{rpm}$. The heart rate was measured and noted after 5 min of work. If it was found to be stable (i.e. varied by less than 5 bpm) at the end of the sixth minute, the last of the two readings was considered as the heart-rate response to this work rate. If not, the test was prolonged by $1 \mathrm{~min}$. Heart rate was recorded using telemetry (Polar Electro Oy, Kempele, Finland). Heart-rate response to the work rate was converted into estimated maximal oxygen uptake, expressed as litres $\mathrm{O}_{2} \times \min ^{-1}$, using the Astrand-Ryhming nomogram (20). Data are presented as absolute values $\left(1 \times \min ^{-1}\right)$, as $\mathrm{ml} \mathrm{O}_{2} \times \min ^{-1} \times \mathrm{kg}^{-1}$ and as $\mathrm{ml} \mathrm{O}_{2} \times \min ^{-1} \times \mathrm{kg}^{-2 / 3}$, the latter according to dimension analysis (17).

\section{Statistics}

Descriptions of data are given as arithmetic mean, its $95 \%$ confidence interval (CI), standard deviation, and the 5th, 25th, median including its $95 \%$ CI, 75th and 95 th percentiles. Since some of the distributions were found to have skew distributions, the $95 \% \mathrm{CI}$ for the median was used throughout the study to describe differences between groups. Data were processed in SPSS, version 10.1 (SPSS, Chicago, IL, USA).

\section{Results}

The height, body mass and BMI of the subjects are given in Tables 1 and 2. At the age of 10 years, medians did not differ and the distributions of height and weight were almost identical between genders. At the age of 13 years, girls were taller and at 16 years boys were both taller and heavier. BMI increased in both genders with increasing age. No difference in BMI between genders was found at the ages of 10 years and 13 years. At 16 years, girls had higher values than boys.

Tables 3 and 4 present data on neuromuscular performance in the six tests in the SIH battery.

Data from the cycle ergometer test are given in Tables 5 and 6 . Absolute values for maximal oxygen uptake increased with age. Relative oxygen uptake decreased with age, in both genders when expressed as $\mathrm{ml} \times \min ^{-1} \times \mathrm{kg}^{-1}$ and in girls when expressed as $\mathrm{ml} \times \min ^{-1} \times \mathrm{kg}^{-2 / 3}$.

Gender differences in physical performance are present in most tests and at most ages. In 10-yearolds, performance on the flexed arm hang and the grip strength tests were better in boys than in girls. Girls aged 10 years performed better on the sit-andreach test, compared with boys. The quiet stand, the vertical jump and cycle ergometry (relative oxygen uptake, $\mathrm{ml} \times \min ^{-1} \times \mathrm{kg}^{-1}$ and $\mathrm{ml} \times \min ^{-1} \times$ $\mathrm{kg}^{-2 / 3}$ ) did not differ between genders. Among 13and 16-year-olds, boys performed better in all tests, except the for quiet stand test, where no difference was found, and the sit-and-reach test, where girls performed better.

\section{Discussion}

This study gives reference values on body mass, body height, BMI and some physical performance tests in Swedish children and adolescents aged 10, 13 and 16 years. Although the participation rate was fairly high, it is reasonable to assume that those who were absent differed from the investigated sample, concerning fitness and anthropometry, in that the studied children probably performed better and were leaner (lower BMI).

Table I. Height, body mass and body mass index (BMI) for girls in the Swedish School-Sports-Health (SIH) sample

\begin{tabular}{|c|c|c|c|c|c|c|c|c|c|c|c|}
\hline & Age (years) & $N$ & Mean & SD & $95 \% \mathrm{Cl}_{\text {mean }}$ & 5th perc. & 25 th perc. & Median & $\left(95 \% \mathrm{Cl}_{\mathrm{md}}\right)$ & 75th perc. & 95th perc. \\
\hline \multirow[t]{3}{*}{ Height (cm) } & 10 & 225 & 139.4 & 6.1 & (138.6 to 140.2 ) & 129.5 & 135.1 & 139.3 & (138.3 to 140.2 ) & 143.5 & 149.3 \\
\hline & 13 & 313 & 158.2 & 6.4 & (I57.5 to I58.9) & 147.5 & 154.0 & 158.5 & (I57.5 to 159.0 ) & 162.5 & 169.8 \\
\hline & 16 & 295 & 164.4 & 6.2 & (163.7 to 165.1$)$ & 154.1 & 160.0 & 164.5 & (163.2 to 165.3$)$ & 168.5 & 175.0 \\
\hline \multirow[t]{3}{*}{ Body mass (kg) } & 10 & 223 & 35.7 & 7.7 & (34.7 to 36.7 ) & 25.9 & 30.4 & 34.3 & (33.1 to 35.5 ) & 39.6 & 50.3 \\
\hline & 13 & 320 & 49.9 & 10.4 & (48.8 to 51.1$)$ & 35.0 & 42.1 & 48.1 & (47.0 to 50.1$)$ & 55.6 & 70.0 \\
\hline & 16 & 298 & 59.2 & 9.9 & (58.0 to 60.3 ) & 44.7 & 52.9 & 58.1 & (57.3 to 59.4 ) & 64.1 & 77.9 \\
\hline \multirow[t]{3}{*}{ BMI $\left(\mathrm{kg} \mathrm{m}^{-2}\right)$} & 10 & 221 & 18.3 & 3.0 & (17.9 to 18.6$)$ & 14.5 & 16.1 & 17.5 & (17.1 to 17.9$)$ & 20.1 & 24.1 \\
\hline & 13 & 306 & 19.9 & 3.4 & (19.5 to 20.2 ) & 15.3 & 17.4 & 19.2 & (18.7 to 19.7$)$ & 21.6 & 26.6 \\
\hline & 16 & 291 & 21.9 & 3.2 & (21.5 to 22.2 ) & 17.8 & 19.8 & 21.3 & (20.9 to 21.7 ) & 23.2 & 28.5 \\
\hline
\end{tabular}

Cl: confidence interval; perc.: percentile. 
Table 2. Height, body mass and body mass index (BMI) for boys in the Swedish School-Sports-Health (SIH) sample

\begin{tabular}{|c|c|c|c|c|c|c|c|c|c|c|c|}
\hline & Age (years) & $\mathrm{N}$ & Mean & SD & $95 \% \mathrm{Cl}_{\text {mean }}$ & 5th perc. & 25 th perc. & Median & $\left(95 \% \mathrm{Cl}_{\mathrm{md}}\right)$ & 75th perc. & 95th perc. \\
\hline \multirow[t]{3}{*}{ Height $(\mathrm{cm})$} & 10 & 282 & 139.7 & 6.3 & (138.9 to 140.4$)$ & 129.6 & 135.4 & 139.3 & (138.5 to 140.2 ) & 143.2 & 151.4 \\
\hline & 13 & 323 & 157.1 & 8.2 & (I56.2 to I58.0) & 145.1 & 151.0 & 156.7 & (I55.5 to I58.I) & 163.0 & 171.1 \\
\hline & 16 & 290 & 175.9 & 6.9 & (I75.I to 176.7$)$ & 164.5 & 171.0 & 175.5 & (174.5 to 177.0$)$ & 181.0 & 187.5 \\
\hline \multirow[t]{3}{*}{ Body mass (kg) } & 10 & 282 & 35.6 & 8.3 & (34.7 to 36.6$)$ & 26.3 & 30.2 & 33.7 & (32.6 to 34.4$)$ & 39.0 & 54.2 \\
\hline & 13 & 324 & 49.6 & 11.5 & (48.3 to 50.8$)$ & 34.4 & 41.1 & 47.9 & (45.8 to 49.8 ) & 54.5 & 72.6 \\
\hline & 16 & 290 & 66.3 & 10.1 & (65.2 to 67.5$)$ & 52.6 & 59.3 & 64.7 & (63.6 to 66.1$)$ & 71.9 & 86.5 \\
\hline \multirow[t]{3}{*}{ BMI $\left(\mathrm{kg} \mathrm{m}^{-2}\right)$} & 10 & 282 & 18.1 & 2.9 & (17.8 to 18.4$)$ & 14.9 & 16.1 & 17.4 & (16.9 to 17.7$)$ & 19.4 & 24.3 \\
\hline & 13 & 323 & 19.9 & 3.6 & (19.5 to 20.3 ) & 15.9 & 17.4 & 19.1 & (18.8 to 19.5$)$ & 21.4 & 27.9 \\
\hline & 16 & 290 & 21.4 & 2.9 & (21.1 to 21.8$)$ & 17.8 & 19.5 & 20.9 & (20.5 to 21.4 ) & 22.7 & 27.1 \\
\hline
\end{tabular}

$\mathrm{Cl}$ : confidence interval; perc.: percentile.

BMI showed a skew distribution, which is in line with other European data $(21,22)$. In all children $20.1 \%$ were overweight or obese using standard definitions (23). These results are similar to recent Danish data (24), except in the oldest girls, where the Danish study showed a considerably higher prevalence $(25 \%$ vs $17.5 \%)$

For the sit-and-reach test, performance improved with age, for both genders, but girls performed better at all ages. This may be due to differences in the growth rate for connective tissue, muscles and bone, but also to the differences between genders in the hip joint and pelvic anatomy. For the quiet stand test, performances improved with age, but no differences were noted between genders. For the flexed arm hang test, performance increased steeply with age, especially in boys. Large gender differences were found in that test. At 16 years of age, more than $50 \%$ of the boys performed better than the top $5 \%$ of the girls. In the vertical jump test, performance increased with age in both groups and so did the difference between genders, with less than $5 \%$ of the 16-year-old girls performing better than the median results for boys. In the sit-ups test, performance differed between genders in 13 and 16year-olds, but not in 10-year-olds. At the age of 10 years, the median for boys did not differ from the median for girls, at 13 years it was close to the 75 th

Table 3. Reference values for girls on the six tests on neuromuscular performance used in the Swedish School-Sports-Health (SIH) study

\begin{tabular}{|c|c|c|c|c|c|c|c|c|c|c|c|}
\hline & Age (years) & $\mathrm{N}$ & Mean & SD & $95 \% \mathrm{Cl}_{\text {mean }}$ & 5th perc. & 25 th perc. & Median & $\left(95 \% \mathrm{Cl}_{\mathrm{md}}\right)$ & 75th perc. & 95th perc. \\
\hline \multirow[t]{3}{*}{ SAR $(\mathrm{cm})$} & 10 & 225 & -0.3 & 7.2 & $(-1.2$ to 0.7$)$ & -12.4 & -6.0 & 0.0 & $(-1$ to 2$)$ & 5.0 & 12.0 \\
\hline & 13 & 313 & 1.4 & 7.7 & (0.5 to 2.2 ) & -12.0 & -4.0 & 2.0 & (I to 3 ) & 7.0 & 13.3 \\
\hline & 16 & 295 & 4.5 & 9.7 & (3.4 to 5.6 ) & -13.0 & -2.0 & 5.0 & (4 to 7 ) & 11.0 & 20.0 \\
\hline \multirow[t]{3}{*}{ QS (ascents) } & 10 & 223 & 5.8 & 5.7 & (5.0 to 6.6 ) & 1.0 & 1.0 & 4.0 & (3 to 4 ) & 9.0 & 16.8 \\
\hline & 13 & 320 & 4.1 & 4.4 & (3.6 to 4.6 ) & 1.0 & 1.0 & 2.0 & (2 to 3 ) & 6.0 & 13.0 \\
\hline & 16 & 298 & 3.5 & 4.0 & (3.0 to 3.9 ) & 1.0 & 1.0 & 2.0 & (I to 2 ) & 5.0 & 12.0 \\
\hline \multirow[t]{3}{*}{ FAH (kgl/3's) } & 10 & 221 & 67.4 & 74.8 & (57.4 to 77.3 ) & 0.0 & 12.9 & 47.2 & (38.9 to 56.1 ) & 88.9 & 222.5 \\
\hline & 13 & 306 & 120.1 & 116.9 & (106.9 to 133.2 ) & 0.0 & 36.9 & 88.9 & (73.5 to 99.3 ) & 172.9 & 371.7 \\
\hline & 16 & 291 & 140.0 & 157.2 & (121.9 to 158.2$)$ & 0.0 & 28.1 & 94.0 & (78.7 to 111.0 ) & 182.4 & 461.8 \\
\hline \multirow[t]{3}{*}{ VJ (kJ) } & 10 & 225 & 85.8 & 24.6 & (82.5 to 89.0$)$ & 54.1 & 68.3 & 83.2 & (79.5 to 85.9 ) & 99.2 & 127.3 \\
\hline & 13 & 314 & 145.4 & 37.1 & (14I.3 to 149.5$)$ & 90.2 & 119.8 & 143.8 & (I38.I to 146.9$)$ & 168.5 & 212.0 \\
\hline & 16 & 295 & 185.5 & 40.5 & (180.9 to 190.2 ) & 120.8 & 158.4 & 185.3 & (179.4 to 189.9 ) & 208.7 & 255.1 \\
\hline \multirow[t]{3}{*}{$\mathrm{SU}(n)$} & 10 & 222 & 13.6 & 5.0 & (13.0 to 14.3 ) & 5.0 & 11.0 & 14.0 & (13 to 15$)$ & 17.0 & 21.0 \\
\hline & 13 & 314 & 17.2 & 4.2 & (16.7 to 17.6$)$ & 10.0 & 15.0 & 17.0 & (16 to 17$)$ & 20.0 & 24.3 \\
\hline & 16 & 293 & 17.8 & 4.3 & (17.3 to 18.3 ) & 11.0 & 15.0 & 18.0 & (17 to 19$)$ & 21.0 & 25.0 \\
\hline \multirow[t]{3}{*}{ GS (kp) } & 10 & 225 & 13.7 & 3.1 & (13.3 to 14.1$)$ & 9.0 & 12.0 & 13.5 & (13 to 14$)$ & 15.5 & 18.9 \\
\hline & 13 & 322 & 22.5 & 5.2 & (21.9 to 23.0$)$ & 14.5 & 19.0 & 22.0 & (21.5 to 22.5 ) & 25.5 & 32.4 \\
\hline & 16 & 299 & 28.3 & 5.4 & (27.7 to 28.9 ) & 19.5 & 24.5 & 28.5 & (27 to 29.5 ) & 32.0 & 37.0 \\
\hline
\end{tabular}

CI: confidence interval; perc.: percentile; SAR: sit-and-reach test; QS: quiet stand balance test; FAH: flexed arm hang test; VJ: vertical jump test; SU: sit-ups test; GS: grip strength test. 
Table 4. Reference values for boys on the six tests on neuromuscular performance used in the Swedish School-Sports-Health (SIH) study

\begin{tabular}{|c|c|c|c|c|c|c|c|c|c|c|c|}
\hline & Age (years) & $\mathrm{N}$ & Mean & SD & $95 \% \mathrm{Cl}_{\text {mean }}$ & 5th perc. & 25 th perc. & Median & $\left(95 \% \mathrm{Cl}_{\mathrm{md}}\right)$ & 75th perc. & 95th perc. \\
\hline \multirow[t]{3}{*}{ SAR $(\mathrm{cm})$} & 10 & 282 & -2.1 & 6.8 & $(-2.9$ to -1.3$)$ & -14.0 & -7.0 & -2.0 & $(-2$ to -2$)$ & 2.0 & 9.0 \\
\hline & 13 & 321 & -3.4 & 7.5 & $(-4.2$ to -2.6$)$ & -15.0 & -9.5 & -3.0 & $(-4$ to -2$)$ & 2.0 & 9.0 \\
\hline & 16 & 291 & -0.5 & 8.6 & $(-1.5$ to 0.5$)$ & -15.0 & -7.0 & 0.0 & $(-2$ to 1$)$ & 5.0 & 13.4 \\
\hline \multirow{3}{*}{ QS (ascents) } & 10 & 281 & 6.1 & 5.9 & (5.4 to 6.8 ) & 1.0 & 2.0 & 4.0 & (3 to 5 ) & 8.0 & 18.0 \\
\hline & 13 & 322 & 3.8 & 4.4 & (3.4 to 4.3 ) & 1.0 & 1.0 & 2.0 & (2 to 3 ) & 5.0 & 11.0 \\
\hline & 16 & 288 & 3.2 & 4.0 & (2.8 to 3.7$)$ & 1.0 & 1.0 & 1.0 & (I to 2 ) & 4.0 & 10.0 \\
\hline \multirow[t]{3}{*}{ FAH (kgl/3's) } & 10 & 273 & 106.4 & 84.3 & (96.3 to 116.4$)$ & 0.0 & 45.4 & 93.7 & (81.4 to 103.9$)$ & 149.3 & 250.5 \\
\hline & 13 & 304 & 205.3 & 185.6 & (184.3 to 226.2 ) & 0.0 & 66.9 & 147.2 & (133.5 to 167.9$)$ & 285.1 & 618.0 \\
\hline & 16 & 282 & 510.3 & 271.7 & (478.5 to 542.2 ) & 85.3 & 317.0 & 501.1 & (456.5 to 535.7$)$ & 679.7 & 1008.7 \\
\hline \multirow[t]{3}{*}{ VJ (kJ) } & 10 & 280 & 88.3 & 24.7 & (85.4 to 91.2 ) & 53.8 & 70.9 & 86.1 & (82.9 to 88.3 ) & 99.9 & 135.8 \\
\hline & 13 & 323 & 159.0 & 45.1 & (154.0 to 163.9 ) & 98.2 & 127.5 & 153.0 & (147.3 to 158.1$)$ & 185.2 & 236.7 \\
\hline & 16 & 285 & 272.9 & 53.1 & (266.7 to 279.1 ) & 196.0 & 237.9 & 268.3 & (262.5 to 277.8 ) & 306.6 & 355.2 \\
\hline \multirow[t]{3}{*}{$\mathrm{SU}(n)$} & 10 & 280 & 14.9 & 4.5 & (14.4 to 15.5$)$ & 8.0 & 12.0 & 15.0 & $(15$ to 16$)$ & 18.0 & 22.0 \\
\hline & 13 & 313 & 20.0 & 5.0 & (19.5 to 20.6$)$ & 12.0 & 17.0 & 20.0 & (19 to 21 ) & 23.0 & 27.3 \\
\hline & 16 & 281 & 23.1 & 4.6 & (22.6 to 23.6$)$ & 15.0 & 20.0 & 23.0 & (22 to 24 ) & 27.0 & 31.0 \\
\hline \multirow[t]{3}{*}{ GS (kp) } & 10 & 279 & 15.9 & 3.4 & (I5.5 to 16.3 ) & 10.5 & 13.5 & 16.0 & (15 to 16$)$ & 18.0 & 22.0 \\
\hline & 13 & 326 & 25.5 & 6.4 & (24.8 to 26.2 ) & 16.0 & 20.5 & 25.0 & (24 to 26$)$ & 29.5 & 38.2 \\
\hline & 16 & 288 & 44.3 & 7.6 & (43.4 to 45.2 ) & 33.0 & 39.0 & 44.5 & (43.5 to 45$)$ & 48.5 & 57.8 \\
\hline
\end{tabular}

$\mathrm{Cl}$ : confidence interval; perc.: percentile; SAR: sit-and-reach test; QS: quiet stand balance test; FAH: flexed arm hang test; VJ: vertical jump test; SU: sit-ups test; GS: grip strength test.

percentile for girls, and at 16 years it was close to the 95 th percentile for girls. In the grip strength test, a steep increase in performance was noted, especially for boys. More than $75 \%$ of boys aged 16 years performed better than the top $5 \%$ of girls. In the cycle ergometry test no difference was found between genders at the age of 10 years, but at 13 and 16 years boys performed better. The results from the cycle ergometer test showed higher values with increasing age, when expressed in absolute values $\left(1 \times \min ^{-1}\right)$, whereas lower values was found with increasing age in both genders when expressed in $\mathrm{ml} \times \min ^{-1} \times \mathrm{kg}^{-1}$ and in girls when expressed in $\mathrm{ml} \times \min ^{-1} \times \mathrm{kg}^{-2 / 3}$. This implies that, with age, the increase in absolute oxygen uptake cannot compensate for the increase in body mass.

Compared with a recent Danish study, the levels of aerobic fitness were somewhat higher in Swedish girls but comparable in boys. In Danish children (aged approximately 9.5 years) studied in 1997-98 (22), the mean maximal oxygen uptake was $42 \mathrm{ml} \times$ $\min ^{-1} \times \mathrm{kg}^{-1}$ for girls and $47 \mathrm{ml} \times \min ^{-1} \times \mathrm{kg}^{-1}$ for boys. Based on data given in the article, the present study found a higher fitness level in girls

Table 5. Reference values for girls on the cycle ergometer test for aerobic fitness in the Swedish School-Sports-Health (SIH) study

\begin{tabular}{|c|c|c|c|c|c|c|c|c|c|c|c|}
\hline & Age (years) & $\mathrm{N}$ & Mean & SD & $95 \% \mathrm{Cl}_{\text {mean }}$ & 5th perc. & 25th perc. & Median & $\left(95 \% \mathrm{Cl}_{\mathrm{md}}\right)$ & 75th perc. & 95th perc. \\
\hline \multirow[t]{3}{*}{$\mathrm{CE}^{\mathrm{a}}$} & 10 & 107 & 1.8 & 0.2 & (I.7 to 1.8$)$ & 1.6 & 1.6 & 1.7 & ( 1.6 to 1.8$)$ & 1.9 & 2.3 \\
\hline & 13 & 273 & 2.1 & 0.4 & (2.0 to 2.1$)$ & 1.6 & 1.8 & 2.0 & $(2.0$ to 2.0$)$ & 2.2 & 2.7 \\
\hline & 16 & 263 & 2.3 & 0.5 & (2.2 to 2.3 ) & 1.6 & 1.9 & 2.2 & (2.1 to 2.2 ) & 2.6 & 3.1 \\
\hline \multirow[t]{3}{*}{$\mathrm{CE}^{\mathrm{b}}$} & 10 & 107 & 49.6 & 9.8 & (47.7 to 51.5$)$ & 33.6 & 43.2 & 48.6 & (47.4 to 52.4$)$ & 56.1 & 68.0 \\
\hline & 13 & 273 & 42.0 & 8.7 & (40.9 to 43.0$)$ & 27.9 & 35.9 & 41.8 & (40.0 to 43.0 ) & 47.9 & 56.5 \\
\hline & 16 & 263 & 38.1 & 7.7 & (37.2 to 39.1 ) & 26.5 & 32.3 & 37.1 & (36.2 to 38.3 ) & 42.8 & 51.3 \\
\hline \multirow[t]{3}{*}{$\mathrm{CE}^{\mathrm{c}}$} & 10 & 107 & 163.1 & 25.3 & (158.2 to 167.9$)$ & 122.3 & 146.2 & 161.5 & (157.0 to 168.0$)$ & 177.8 & 211.5 \\
\hline & 13 & 273 & 153.2 & 26.6 & (150.0 to 156.4$)$ & 111.2 & 136.8 & 151.6 & (I46.0 to I56.5) & 171.0 & 200.1 \\
\hline & 16 & 263 & 147.9 & 27.8 & (144.5 to 151.3 ) & 107.9 & 127.5 & 143.8 & (140.8 to 149.1 ) & 166.3 & 197.7 \\
\hline
\end{tabular}

$\mathrm{Cl}$ : confidence interval; perc.: percentile; $\mathrm{CE}$ : cycle ergometry.

${ }^{\text {a }}$ Expressed as $1 \times \mathrm{kg}^{-1}$.

${ }^{b}$ Expressed as $\mathrm{ml} \times \mathrm{min}^{-1} \times \mathrm{kg}^{-1}$.

${ }^{c}$ Expressed as $\mathrm{ml} \times \mathrm{min}^{-1} \times \mathrm{kg}^{-2 / 3}$. 
Table 6. Reference values for boys on the cycle ergometer test for aerobic fitness in the Swedish School-Sports-Health (SIH) study

\begin{tabular}{|c|c|c|c|c|c|c|c|c|c|c|c|}
\hline & Age (years) & $N$ & Mean & SD & $95 \% \mathrm{Cl}_{\text {mean }}$ & 5th perc. & 25th perc. & Median & $\left(95 \% \mathrm{Cl}_{\mathrm{md}}\right)$ & 75th perc. & 95th perc. \\
\hline \multirow[t]{3}{*}{$\mathrm{CE}^{\mathrm{a}}$} & 10 & $|4|$ & 1.8 & 0.2 & ( 1.8 to 1.8$)$ & 1.6 & 1.6 & 1.7 & (I.7 to 1.8$)$ & 1.9 & 2.2 \\
\hline & 13 & 295 & 2.2 & 0.4 & (2.1 to 2.2 ) & 1.6 & 1.8 & 2.1 & (2.0 to 2.2 ) & 2.4 & 2.9 \\
\hline & 16 & 272 & 2.7 & 0.5 & (2.7 to 2.8 ) & 1.9 & 2.3 & 2.7 & (2.6 to 2.8$)$ & 3.1 & 3.6 \\
\hline \multirow[t]{3}{*}{$\mathrm{CE}^{\mathrm{b}}$} & 10 & $|4|$ & 49.4 & 9.3 & $(47.9$ to 51.0$)$ & 33.3 & 43.2 & 50.1 & (47.8 to 51.9 ) & 56.4 & 64.2 \\
\hline & 13 & 295 & 44.4 & 9.3 & (43.4 to 45.5$)$ & 27.9 & 38.7 & 44.4 & (43.2 to 45.9$)$ & 50.6 & 59.7 \\
\hline & 16 & 272 & 41.6 & 8.5 & (40.6 to 42.6 ) & 27.9 & 36.2 & 41.1 & (39.9 to 42.4 ) & 47.2 & 56.4 \\
\hline \multirow[t]{3}{*}{$\mathrm{CE}^{\mathrm{c}}$} & 10 & $|4|$ & 162.6 & 22.5 & (158.9 to 166.4 ) & 121.1 & 148.2 & 162.8 & (159.1 to 167.3$)$ & 178.3 & 200.9 \\
\hline & 13 & 295 & 161.4 & 28.7 & (158.I to 164.7$)$ & 111.9 & 143.2 & 160.1 & (I55.7 to 162.5 ) & 179.9 & 211.3 \\
\hline & 16 & 272 & 167.4 & 31.9 & (163.6 to 171.2$)$ & 114.9 & 145.8 & 166.4 & $(160.1$ to 170.4$)$ & 190.2 & 220.2 \\
\hline
\end{tabular}

$\mathrm{Cl}$ : confidence interval; perc.: percentile; $\mathrm{CE}$ : cycle ergometry.

${ }^{\text {a }}$ Expressed as $1 \times \mathrm{kg}^{-1}$.

${ }^{\mathrm{b}}$ Expressed as $\mathrm{ml} \times \mathrm{min}^{-1} \times \mathrm{kg}^{-1}$.

c Expressed as $\mathrm{ml} \times \mathrm{min}^{-1} \times \mathrm{kg}^{-2 / 3}$

(mean difference $7.4 \mathrm{ml} \times \mathrm{min}^{-1} \times \mathrm{kg}^{-1}, 95 \% \mathrm{CI}$ 5.8 to $9.3 \mathrm{ml} \times \min ^{-1} \times \mathrm{kg}^{-1}$ ). In boys the difference was only $2.0 \mathrm{ml} \times \mathrm{min}^{-1} \times \mathrm{kg}^{-1}(95 \%$ CI 0.2 to $3.7 \mathrm{ml} \times \min ^{-1} \times \mathrm{kg}^{-1}$ ).

One possible explanation for the gender differences for 10-year-olds in these comparisons may be the difference in sampling year (1997-98 in the Danish study and 2001 in the present study), and that the genders have had differing secular trends.

However, it is possible that Swedish and Danish girls (but not boys) actually differ regarding aerobic fitness, since the samples also differ in other key aspects. For example, the Swedish girls were taller (mean difference $1.4 \mathrm{~cm}, 95 \%$ CI 0.4 to $2.4 \mathrm{~cm}$ ) and heavier (mean difference $2.7 \mathrm{~kg}, 95 \%$ CI 1.5 to $3.9 \mathrm{~kg}$ ) than their Danish peers. It is important to underline that these differences only concern 10-year-old children.

The lower levels of relative oxygen uptake $\left(V \mathrm{O}_{2}\right.$ max $)$ in 16-year-olds compared with in the present study may describe a natural development regarding relative oxygen uptake between the ages of 10 and 16 years. The latter has been shown previously (6) in girls, but not in boys. The decreasing levels across age groups could therefore be a consequence of a physically inactive lifestyle during adolescence and should therefore raise concern among health promoters and public health professionals.

An earlier study (16), showed that boys aged 16 years had lower levels of aerobic fitness in 2001 than in 1987. No such trend were found in girls aged 16 years. However, in another study, Jansson and Hedberg (25) showed values from 1991 on aerobic fitness in adolescents. In that study, mean absolute oxygen uptake were 2.1 and $2.71 \times \mathrm{min}^{-1}$ for girls and boys, respectively. Relative oxygen uptake was 36.3 and $43.1 \mathrm{ml} \times \min ^{-1} \times \mathrm{kg}^{-1}$ for girls and boys, respectively. These results are close to the results in the present study, for both boys and girls. Thus, no obvious trend seems to be present.

In the sit-and-reach test, girls had a superior performance to boys in all age groups. This is in line with earlier studies $(26,27)$.

One potential confounder is level of maturity (28, 29). Maturity data (such as Tanner status) were not collected from these subjects, for practical reasons. Data in the present study should therefore be considered as data on the general population at the ages of 10, 13 and 16 years in 2001. However, a slow secular trend towards earlier puberty has been reported (30), implicating that results from older studies may differ to those in the present study, partly owing to differences in maturation. If so, the older samples should be less mature and thereby be handicapped by a less developed physical capacity.

One important conclusion from this study was that gender and age differences are present, but that the differences in performance between individuals within an age or gender group are large. The common view that boys are physically superior to girls and that older children are better than younger can be complemented by the data shown in this study. The results show, for example, that there is a limited physiological rationale to divide children by gender in sports or activities where success is mainly based on balancing ability. However, when the results depend on upper body strength (as measured in the present study by the grip strength and flexed arm hang tests), only a few girls will perform better than the average boy, especially in children older 
than 13 years. Another practical use of the present data may be their use as reference data in comparisons with, for example, children with impairments or different diseases, or in habilitation or rehabilitation after injuries.

\section{References}

1. Takken T, Terlingen HC, Helders PJ, Pruijs H, Van der Ent CK, Engelbert RH. Cardiopulmonary fitness and muscle strength in patients with osteogenesis imperfecta type I. J Pediatr 2004; 145: 813-8.

2. van Brussel $M$, Takken $T$, Lucia A, van der Net J, Helders PJ. Is physical fitness decreased in survivors of childhood leukemia? A systematic review. Leukemia 2005; 19: 13-7.

3. Takken T, Spermon N, Helders PJ, Prakken AB, Van Der Net J. Aerobic exercise capacity in patients with juvenile dermatomyositis. J Rheumatol 2003; 30: 107580

4. Bencke J, Damsgaard R, Saekmose A, Jorgensen P, Jorgensen K, Klausen K. Anaerobic power and muscle strength characteristics of 11 years old elite and nonelite boys and girls from gymnastics, team handball, tennis and swimming. Scand J Med Sci Sports 2002; 12: $171-8$.

5. Damsgaard R, Bencke J, Matthiesen G, Petersen JH, Muller J. Body proportions, body composition and pubertal development of children in competitive sports. Scand J Med Sci Sports 2001; 11: 54-60.

6. Sunnegardh J, Bratteby LE. Maximal oxygen uptake, anthropometry and physical activity in a randomly selected sample of 8 and 13 year old children in Sweden. Eur J Appl Physiol Occup Physiol 1987; 56: 266-72.

7. Barnekow-Bergkvist M, Hedberg G, Janlert U, Jansson E. Development of muscular endurance and strength from adolescence to adulthood and level of physical capacity in men and women at the age of 34 years. Scand J Med Sci Sports 1996; 6: 145-55.

8. Westerstahl M, Barnekow-Bergkvist M, Hedberg G, Jansson E. Secular trends in body dimensions and physical fitness among adolescents in Sweden from 1974 to 1995. Scand J Med Sci Sports 2003; 13: 128 37.

9. Dyrstad SM, Aandstad A, Hallen J. Aerobic fitness in young Norwegian men: a comparison between 1980 and 2002. Scand J Med Sci Sports 2005; Online publication DOI: $10.1111 /$ j.1600-0838.2005.00432.×:

10. Wedderkopp N, Froberg K, Hansen HS, Andersen LB. Secular trends in physical fitness and obesity in Danish 9-year-old girls and boys: Odense School Child Study and Danish substudy of the European Youth Heart Study. Scand J Med Sci Sports 2004; 14: 150-5.

11. Lefevre J, Philippaerts R, Delvaux K, Thomis M, Claessens AL, Lysens R, et al. Relation between cardiovascular risk factors at adult age, and physical activity during youth and adulthood: the Leuven Long- itudinal Study on Lifestyle, Fitness and Health. Int $\mathbf{J}$ Sports Med 2002; 23(Suppl 1): S32-8.

12. Beunen G, Ostyn M, Simons J, Renson R, Claessens AL, Vanden Eynde B, et al. Development and tracking in fitness components: Leuven longitudinal study on lifestyle, fitness and health. Int J Sports Med 1997; 18 Suppl 3: S171-8.

13. Kemper HC, Snel J, Verschuur R, Storm-van Essen L. Tracking of health and risk indicators of cardiovascular diseases from teenager to adult: Amsterdam Growth and Health Study. Prev Med 1990; 19: 642-55.

14. Kemper HC, Twisk JW, Koppes LL, van Mechelen W, Post GB. A 15-year physical activity pattern is positively related to aerobic fitness in young males and females (13-27 years). Eur J Appl Physiol 2001; 84: 395402.

15. Adam C, Klissouras V, Ravassolo M. Eurofit. Handbook for the Eurofit test of physical fitness. Rome: Council of Europe, Committee for the Development of Sport; 1988.

16. Ekblom O, Oddsson K, Ekblom B. Health-related fitness in Swedish adolescents between 1987 and 2001. Acta Paediatr 2004; 93: 681-6.

17. Åstrand P-O, Rohdahl K. Textbook of work physiology. Physiological bases of exercise. New York: McGraw-Hill Book Company; 1986.

18. Jaric S, Mirkov D, Markovic G. Normalizing physical performance tests for body size: a proposal for standardization. J Strength Cond Res 2005; 19: 467-74.

19. Markovic G, Jaric S. Movement performance and body size: the relationship for different groups of tests. Eur $\mathbf{J}$ Appl Physiol 2004; 92: 139-49.

20. Åstrand P-O, Ryhming I. A nomogram for calculation of aerobic capacity (physical fitness) from pulse rate during submaximal work. J Appl Physiol 1954; 7: 218 21.

21. Kautiainen S, Rimpela A, Vikat A, Virtanen SM. Secular trends in overweight and obesity among Finnish adolescents in 1977-1999. Int J Obes Relat Metab Disord 2002; 26: 544-52.

22. Wedderkopp N, Froberg K, Hansen HS, Andersen LB. Secular trends in physical fitness and obesity in Danish 9-year-old girls and boys: Odense School Child Study and Danish substudy of the European Youth Heart Study. Scand J Med Sci Sports 2004; 14: 150-5.

23. Cole TJ, Bellizzi MC, Flegal KM, Dietz WH. Establishing a standard definition for child overweight and obesity worldwide: international survey. BMJ 2000; 320: $1240-3$.

24. Pearson S, Olsen LW, Hansen B, Sorensen TI. [Increase in overweight and obesity amongst Copenhagen schoolchildren, 1947-2003]. Ugeskr Laeger 2005; 167: 15862 .

25. Jansson E, Hedberg G. Skeletal muscle fiber types in teenagers: relation to physical performance and activity. Scand J Med Sci Sports 1991; 1: 31-4.

26. Eisenmann JC, Malina RM. Age- and sex-associated variation in neuromuscular capacities of adolescent distance runners. J Sports Sci 2003; 21: 551-7. 
27. Butterfeld SA, Lehnhard RA, Coladarci T. Age, sex, and body mass index in performance of selected locomotor and fitness tasks by children in grades K-2. Percept Mot Skills 2002; 94: 80-6.

28. Volver A, Viru A, Viru M. Improvement of motor abilities in pubertal girls. J Sports (GIH) Med Phys Fitness 2000; 40: 17-25.

29. Delgado A, Allemandou A, Peres G. Changes in the characteristics of anaerobic exercise in the upper limb during puberty in boys. Eur J Appl Physiol Occup Physiol 1993; 66: 376-80.
30. Karlberg J. Secular trends in pubertal development. Horm Res 2002; 57 Suppl 2: 19-30.

\section{Örjan Ekblom,}

Åstrand Laboratory for Work Physiology

University College of Physical Education and Sports

PO Box 5626, SE-II4 86 Stockholm

Sweden

Tel: +468161463

Fax: +46866075 II

E-mail: orjan.ekblom@gih.se 